\title{
USOS DEL ESPACIO PÚBLICO EN LA CIUDAD DE RIO DE JANEIRO DE LOS MEGAEVENTOS
}

\author{
Nilton SILVA DOS SANTOS \\ Universidade Federal Fluminense (Brasil) \\ ninisants@gmail.com
}

\begin{abstract}
USES OF THE PUBLIC SPACE IN THE CITY OF RIO DE JANEIRO OF MEGAEVENTS 1
\end{abstract}

Resumen: En este artículo intentaremos analizar como la política de ordenamiento y represión del ayuntamiento de la ciudad de Río de Janeiro, llamada "Choque de Ordem", ha sido impuesta en distintos sitios de la metrópoli. Intentaremos comprender su génesis, analizando las políticas de regulación y comportamiento de los ciudadanos cariocas, en un proceso de civilización, en el sentido de Elias, que ha obtenido apoyo, sobretodo de los medios de comunicación de masivos. Al mismo tiempo la regulación y la privatización de los espacios públicos ha cerrado, sobremanera, usos rebeldes y insumisos por parte de numerosos actores sociales, como vendedores de mercancía en la calle, Bailarines del carnaval, moradores callejeros, movilizaciones cívicas y sociales, etc. Comprender la "naturaleza sociológica del conflicto" (Simmel) en curso en la arena urbana, en su multiplicidad de procesos de interacciones y de mediaciones, revelará la presencia surda de disputas por la atribución de eficacia simbólica (Delgado:2003) al espacio público y a los suyos usos.

Abstract: We will try in this article to analyze how the urban planning and repression policy of the municipality of the city of Rio de Janeiro, known as "Shock of Order", has been imposed in different locations in the metropolis. We will also try to understand its genesis, analyzing the policies regulating the behavior of the carioca citizen, in a process of civilization, in the Elias sense, which gained support mainly of the mass media. At the same time the regulation and privatization of public spaces blocked in a significant way any rebellious and insurgent use by uncountable social actors like street vendors, carnival dancers, people living in the streets, as well as mobilizations by social movements, etc. To understand the "sociological nature of the conflict" (Simmel) taking place in the urban arena, in its multiple process of interactions and mediations, will uncover the silent presence of disputes for assignment of symbolic effectiveness (Delgado:2003) to public space and its uses.

Palabras clave: Ciudad; Río De Janeiro; Conflitos Urbanos; Espacio Público; Gentrificacción Río De Janeiro; Urban Conflicts; Public Space; Gentrification

1 Traducción del portugués de Elsa Patiño Tovar, DIAU-UAP. 
Hoje tem baile funk, tem samba no Flamengo, um reverendo no palanque lendo o Apocalipse (...) Cidade maravilhosa, és minha, o poente na espinha das tuas montanhas quase arromba a retina de quem vê (Chico Buarque, "Carioca", 2006).

Pensar la ciudad, la metrópoli o el espacio público, han sido una de las tareas más desafiantes, estimulantes y fructíferas, en las que los investigadores, en diversas áreas, vienen trabajando desde Georg Simmel, por lo menos. La lección simmeliana de que "la sociedad es meramente el nombre dado para un número de individuos conectados por la interacción", nos sirve como punto de partida.

En ese espacio metropolitano, un sinnúmero de fenómenos se desarrollan con sus actores sociales y sus particularidades, a la espera de lectores preparados para la reflexión. Las fiestas populares, los mega-eventos, las procesiones, los comicios, los conflictos de la calles, el trueque entre vecinos, las marchas religiosas o las del orgullos gay, etcétera, son locus privilegiados para esa lectura analítica a partir de los materiales que tenemos disponibles.

Los trabajos de diversos estudiosos toman el conflicto urbano como momento propicio para pensar sus conexiones con el poder, lo lúdico, la mediación cultural, los modos de producción y reproducción tradicionales, entre otros temas. Sin embargo, ese ofrecerse al disfrute que la calle actualiza, no debe disimular la presencia de sordas disputas en curso por atribuir una eficacia simbólica (Delgado, 2003) propia de lo urbano y sus múltiples dimensiones. Manuel Delgado (2003: 13), en su libro Carrer, festa i revolta: els usos simbòlics de l'espai públic a Barcelona (1951-2000), al discutir los usos simbólicos del espacio público, observa que las fiestas populares, por ejemplo, no son espacios solamente armónicos y de culto al pasado, también, en esos eventos, los conflictos no son materia extraña a las costumbres; las fiestas anuncian las virtualidades, las energías y las potencialidades que se expresan en tiempo haciendo, deshaciendo y rehaciendo a la sociedad.

En este artículo, procuro analizar de qué manera, la política de ordenación y control de la Prefectura Municipal de Río de Janeiro, titulada “Choque de Orden”, ha sido aplicada en los diferentes espacios de la ciudad. Pretendo entender su génesis, analizándola como fruto de políticas regulatorias de las conductas y de los comportamientos de los ciudadanos cariocas en un proceso civilizatorio, en un sentido eliasiano, que ha tenido apoyo, sobre todo de los medios de comunicación de masas. ${ }^{1} \mathrm{Al}$ mismo tiempo, la regulación y la privatización de los espacios públicos han impedido, sobre manera, usos "rebeldes" por parte de importantes actores sociales, tales como vendedores ambulantes, participantes del carnaval, moradores de la calle, marchas de movimientos sociales, etc.

Claro que estas prácticas regulatorias, higienistas y de control social, no surgieron de la noche a la mañana, sino que han sido experimentadas a lo largo de los años en la historia republicana brasileña en la ciudad de Río de Janeiro. Uno de los marcos de la utilización de prácticas urbanísticas para el control de las clases populares, en sentido muy amplio, puede ser apuntado con el proceso conocido como "Bota-Abajo" que formuló el perfil del centro de la ciudad de Río de Janeiro, en el tránsito del siglo XIX al XX.

Como bien lo describe el historiador José Murilo de Carvalho, en su clásico libro $O s$ Bestializados:en Río de Janeiro y la República que no fue, la demolición de conventillos, como el famoso "Cabeça de Porco" -que abrigaba, aproximadamente, cuatro mi personas en 1892- por el entonces prefecto Barata Ribeiro, es una de las marcas de este proceso de "limpieza urbana" que redundará en el nacimiento de la primera favela del país, situada en

1 Ver Santos (2006), "Festa, sociabilidade e espaço público: reflexões de um turista acidental naFesta de la Mare de Deu de la Mercè em Barcelona, Catalunya" en Textos escolhidos de cultura e arte populares, Rio de Janeiro, v.3, n.1, pp. 63-70. 
el Morro da Favella (actualmente Favela da Providência). A lo cual se suma la destrucción de otros seiscientos conventillos(en los cuales habitaba $25 \%$ de la población de la ciudad de Río de Janeiro), la construcción de avenidas amplias como la Avenida Central (hoy llamada Avenida de Rio Branco, inaugurada con fiesta el 15 de noviembre de 1905) y la Avenida Beira-Mar (inspirada fuertemente en las ideas de la Europa de la época), obras que fueron conducidas personalmente por el entonces prefecto Pereira Passos² (1902-1906).

Tales operaciones, en la configuración espacial de la ciudad, se volvieron el símbolo distintivo de la modernidad. José Murilo de Carvalho (1998: 30) llama la atención hacia la "prevención republicana contra pobres y negros" que se manifestó en la persecución promovida por el jefe de policía del Distrito Federal en el gobierno de Deodoro da Fonseca, Sampaio Ferraz, por ejemplo, en la lucha contra los capoeiristas, ${ }^{3}$ los bicheiros ${ }^{4}$ y la destrucción de las formas de vivienda popular, además de las campañas higienistas de vacunación.

En Brasil, somos, usualmente, influenciados por ideas exógenas, como el liberalismo político, y muchos de nuestros liberales defendieron la esclavitud como forma de producción para el país, en la transición del Imperio a la República. En ese sentido, una de las más recientes importaciones hechas fue la doctrina de la Tolerancia Cero, originalmente creada en Estados Unidos, en el marco del gobierno de Nueva York bajo la administración de Rudolph Giuliani.

En la ciudad de Río de Janeiro, esta medida se materializa en la llamada Operación "Choque de Orden" que visualiza "combatir el desorden en los espacios públicos" y que viene realizando, sistemáticamente, operaciones en contra de predios clandestinos y/o construcciones irregulares, comercio ilegal (camelôs) y polución visual. En términos generales, la poco precisa y genérica noción de "caos urbano" sirve como ancla para esa ideología de control y de reglamentación de la ciudad y de sus ciudadanos. Tanto así, que casi todo ha sido blanco de la operaciones de la Secretaría Especial del Orden Público (SEOP) que, en poco más de cuatro años, realizó más de cuatro mil intervenciones regulatorias de toda especie, como, por ejemplo, la destrucción de treinta y cuatro inmuebles del Recreio dos Bandeirantes (Zona Oeste de la ciudad), el retiro de sesenta y ocho moradores de la calle, multa a ciento sesenta y siete autos y el encarcelamiento de dos personas, segúninformó el diarioZero Hora de PortoAlegre, ${ }^{5}$ del 8 de enero de 2009.

En el portal (web) de la Prefectura de la Ciudad de Río de Janeiro, se lee que "Choque de Orden" sería:

\section{El fin del desorden urbano. \\ El desorden urbano es el gran catalizador de la sensación de inseguridad pública y el generador de las condiciones que propician la práctica criminal, de forma general. Como una cosa lleva a la otra, esas situaciones proscriben a las personas y a los buenos principios de las calles, contribuyendo a la degeneración, la desocupación de estos espacios y la reducción de la actividades económicas. \\ Con el objetivo de poner fin al desorden urbano, combatir los pequeños delitos}

2 La Prefectura de la ciudad de Río de Janeiro tiene un instituto de urbanismo cuyo nombre homenajea a Pereira Passos. En el Instituto Pereira Passos, fuimos informados que el IPP coordinó grandes proyectos urbanos como el Rio Cidades, la Favela Bairro, el Rio Orla y el Porto Maravilha.

3 N. de R.: La capoeira, de origen africano, mezcla de lucha, juego y danza, fue utilizada como forma de resistencia en contra de la esclavitud.

4 N. de R.: El bicheiro es la denominación de los apostadores en juegos ilegales que utilizan animales (bichos) en sorteos tipo lotería que se realizan todos los días. Los bicheiros usualmente están vinculados a las escuelas de samba de Río de Janeiro como patronos.

5 La repercusión mediática nacional demuestra cierto consenso sobre la validez de la iniciativa de reglamentación de los espacios públicos en la ciudad de Río de Janeiro. 
en los principales corredores, contribuir decisivamente en la mejoría de la calidad de vida en nuestra Ciudad, fue creada la Operación Choque de Orden. Son operaciones realizadas por la recién creada Secretaría de Orden Público, que en un año de existencia viene consiguiendo devolver el orden a la ciudad ${ }^{6}$

Es importante subrayar que las iniciativas de la administración municipal vinieron con la estela de realizaciones de los Juegos Pan-Americanos de Río de Janeiro en 2007. Ahora, debemos también destacar que la prefectura de la ciudad de Río de Janeiro firmó contrato con la Rudy's Giuliani, firma de consultoría en seguridad del ex-prefecto de Nueva York, para asesorar a la ciudad en la preparación de la candidatura a sede de los Juegos Olímpicos de 2016.

Otra empresa contratada, por la prefectura de Río, fue la catalana PromocióCiutat Vella S. A. (PROCIVESA), con la finalidad de contribuir a la candidatura Olímpica de la ciudad de Río de Janeiro. El cuadro de actuación nociva de esta empresa en la ciudad de Barcelona es ampliamente tratada en la tesis de Miquel Fernández, Matar al Chino. Entre la revolución urbanística y el asédio urbano en el barrio del Raval de Barcelona, presentada hace poco en la Universidad de Barcelona. Además, desde el gobierno del prefecto César Maia (1993-1996 y 2000-2008), de donde salió un joven liderazgo conservador, el actual prefecto de la ciudad de Río de Janeiro, Eduardo Paes, “adoptó en Río de Janeiro un nuevo patrón de gestión urbana, de orientación neoliberal, que sigue esencialmente los principios del planeamiento estratégico con influencia directa del modelo catalán. Se debe destacar que la realización de megaeventos estaba presente, como estrategia, en el primer Plan Estratégico de 1996, y que la actual conquista marca una posibilidad renovada de construcción de hegemonía con la afirmación de tal proyecto. Entretanto, como indica la literatura, este gigantesco esfuerzo de city marketing viene asociado a altos costos para asegurar la posición de las ciudades sede" (Sanchez, Bienestein y Mascarenhas, 2010). ${ }^{7}$ Dicho de otra manera, la ciudad de Río de Janeiro vive remociones de población de áreas de "interés olímpico", gentrificación y reorganización del espacio urbano. ${ }^{8}$

La candidatura de Río de Janeiro a Ciudad Olímpica fue victoriosa, en una alianza que juntó al entonces presidente de la República, Luís Inácio Lula da Silva (PT), al gobernador del Estado de Río de Janeiro, Sergio Cabral (PMDB), y al prefecto Eduardo Paes (PMDB). El anuncio de la victoria de Brasil, en Copenhague, ocurrió el 2 de octubre de 2009, y el presidente Lula afirmó que tal victoria era el marco de la conquista de nuestra "ciudadanía internacional". No necesitamos hacer largas citaciones de Loïc Wacquant ${ }^{9}$ para saber que el desmontaje del Estado de Bienestar (Welfare State) es a costa del incremento del Estado penal.

Parece ser éste el encuadramiento en el cual está la ciudad de Río de Janeiro (RJ), en otras palabras, el de la criminalización de la pobreza y de los movimientos populares, además de la imposición de patrones originarios de esquemas y planes estratégicos de desarrollo. El no reconocimiento de los valores y significados atribuidos por los populares a su espacio de vivienda, por ejemplo, por parte de los planificadores urbanos, ya fue tratada en el clásico libro de Herbert J. Gans, The Urban Villagers: Group and Class in the Life of Italian-Americans (1962), a propósito de la remodelación de un barrio del West End en Boston.

Para explicitar el argumento, a propósito del incremento del aparato represivo en la ciu-

6 http://www.rio.rj.gov.br/web/guest/exibeconteudo?article-id=87137

7 Para mayores detalles, ver el libro organizado por los autores: O jogo continua: megaeventos esportivos e cidades (2011).

8Christopher GAFFNEY. "Megaeventos e dinâmicassócio-espaciais no Rio de Janeiro, 1919-2016" en Journal of Latin American Geography, 9-1, 2010.

9As prisões da miséria, Rio de Janeiro, Jorge Zahar, 1999. 
dad, podemos presentar otro caso reciente. El 5 de septiembre de 2011, 420 oficiales de la Guardia Municipal, patrullaron el centro de la ciudad de Río de Janeiro, durante 24 horas. La operación cubrió setenta calles y plazas, inclusive Cinelândia, espacio simbólico de las movilizaciones ciudadanas (Movimento Diretas Já, por ejemplo) en la ciudad. La instrucción de la Guardia era actuar sobre los vendedores ambulantes y los panfleteros, ocupando el espacio público. Cada guardia estaba equipado con un GPs ligado a la central de operaciones, en el cual se podía reportar, en tiempo real, cualquier tipo de irregularidad, además de portar armas no letales, como teasers y spray pimienta, y canes adiestrados. Subráyese que el énfasis represor incide en los trabajadores informales, vendedores ambulantes y subempleados en la distribución de propaganda en folletos. Esta fuerza se ha constituido en cuerpo represivo fijo representado por la Unidad de Orden Público (UOP).

En Tijuca, barrio de la Zona Norte de la ciudad, de perfil tradicional y que vota por candidatos de centro en la elecciones, la prefectura montó una UOP con 220 guardias municipales para patrullar, aproximadamente, cuarenta calles, dando énfasis al combate a los crímenes de la calles y los estacionamientos de automóviles en sitios irregulares. La fiscalización se aplica también al transporte de pasajeros en vans, taxis y moto-taxis, además de displays promocionales en comercios y mercados.

Aunque los diarios y programas policíacos de radio y televisión (éstos son muy populares en la ciudad) apoyan ampliamente la "política de ordenación urbana", algunas voces disonantes aparecen. Un habitante de Tijuca, por ejemplo, declaró que la Operación "Choque de Orden", fue una mala iniciativa porque incide sobre las personas que están trabajando y tienen sus mercancías confiscadas por los guardias municipales. Esas personas necesitan de estos productos para sobrevivir. Ellos no ofrecen ninguna alternativa para que estas personas sobrevivan". Ese habitante relató que un policía expulsó a un hombre con limitaciones de movimiento que cantaba en la calles a cambio de algunas monedas.

Tal política de regulación del espacio público se repite por toda la ciudad de Río de Janeiro. En Ipanema, Zona Sur de la ciudad, en uno de los accesos al Morro Pavão-Pavãozinho, un depósito utilizado por ambulantes y pepenadores de lata para reciclaje, todo su material fue confiscado. En Copacabana, isopores, bebidas, sillas, sombrillas y carritos (los llamados "burros-sin-rabo") fueron decomisados, y un trabajador fue detenido y llevado a la delegación por no tener documento con foto. En Lapa, Zona Central y bohemia de la ciudad, un depósito fue invadido por policías y fiscales de la prefectura, que se llevaron toda la mercancía (comidas, bebidas, sillas, isopores, etcétera) sin entregar laudo de decomiso alguno a los responsables del lugar. Una trabajadora indignada dijo que:

La gente está una situación ruin por falta de empleo. Ni para trabajar la gente ayuda. Vea ahí, ¡se están llevando todo!

También en Lapa, los habitantes de la ocupación Carlos Marighella, que alberga, aproximadamente, sesenta familias, fue invadido, y las mercancías del lugar fueron llevadas y tiradas en un camión de basura. Una trabajadora de 54 años, vendedora de verduras y legumbres en las calles del centro en los últimos diez años, afirma:

La gente no tiene ya respeto. No importa la edad, tienes que correr porque ellos [los agentes de la prefectura] no quieren saber si eres viejo o nuevo. Ellos roban todo y si discutes todavía te apañan. Mis piernas ya no aguantan más esa vida, pero no puedo dejar eso porque es todo lo que tengo. Crio una nieta sola porque mi hija murió y mis cuentas ya se están acumulando. ¿Cómo voy a pagar cuenta si no me dejan trabajar? 
Un vendedor de CD's y DVD's, habitante de Queimados, en la Baixada Fluminense, hace un viaje de una hora y media en tren para vender sus mercancías en el centro de Río,y afirma:

Yo no encuentro que eso vaya a mejorar, está dejando mucha gente sin trabajo. En donde vivo todo el día viene alguien que yo conozco a decir que el patrón manda ahora. Y ahí va trabajar a dónde? En la calle, que ni yo. Cuanto más ellos quieren acabar con el camelô, más camelô aparece. En donde vivo conozco mucho camelô. Mucha gente depende de eso para sostener a su familia.

Esas iniciativas represivas de la municipalidad han hecho que los trabajadores a veces se enfrenten físicamente a los fiscales del "Choque de Orden". Tal conflagración resulta en trabajadores y guardias municipales heridos. Vale decir que, sin embargo, en las coberturas televisivas, las tácticas de enfrentamiento utilizadas por los vendedores ambulantes son comparadas a las del tráfico de drogas.Esa interpretación de los medios de comunicación refuerza, sobremanera, la perspectiva criminalizante y discriminadora sobre los trabajadores de la calle.

El panorama no ha movilizado fuertemente a los ciudadanos en defensa de sus derechos. Tal vez, el resultado de las elecciones municipales terminadas en el mes de octubre de 2012 nos muestre que la lucha por la eficacia simbólica (Delgado, 2003) está siendo vencida por los "controladores del orden" de planta. El prefecto Eduardo Paes fue electo para un segundo mandato, teniendo como vice-alcalde a un cuadro político tradicional del Partido de los Trabajadores de RJ, con un arco de alianzas compuesto por más de veinte partidos políticos, en la primera votación realizada. Durante sus programas electorales en la televisión, el énfasis recaía en las transformaciones urbanas vividas por la ciudad. El propio Paes protagonizó una cena inusitada durante la campaña electoral: un actor, caracterizado como el exprefecto Pereira Passos, mentor de las grandes transformaciones urbanas de la aurora de la República, posó al lado del prefecto.

Muchas de esas reformas han contado con el apoyo del gobierno federal, de Lula da Silva y Dilma Rousseff, del Partido de los Trabajadores, que fueron tomados como una perspectiva neodesarrollista en sus mandatos. La transformación de Río de Janeiro en ciudad de la Copa del Mundo de la FIFA en 2014, de la Jornada Mundial de la Juventud (JMJ) y de los Juegos Olímpicos en 2016, catalizó esta situación a tal punto que vemos muchos intelectuales actuando, colaborativamente, en algunas iniciativas "sociales" de la prefectura, ${ }^{10}$ como en el caso de las llamadas Unidades de Policía Pacificadora (UPP’s).

$$
* * *
$$

Mucha de la inversión hecha en la Zona Central de la ciudad de Río, sobre todo, en la Zona Portuaria, fue dirigida al proyecto Porto Maravilha, Operación Urbana Consorciada del Área Especial de Interés Urbanístico de la Región Portuaria de Río de Janeiro, que cambió la cara de esa región, la cual ya fue conocida como la Pequeña África de Río de Janeiro, por la presencia de negros y negras que ahí eran comercializados, en el área de Pedra do Sal, durante la esclavitud y que, posteriormente, se quedaron en la localidad y en los barrios vecinos. Ésta es el área, también, en la cual se identifica el nacimiento de la samba en la ciudad, en los inicios del siglo xx.

La Plaza Mauá, área tradicional frecuentada por habitantes del Morro da Conceição

10 Ver, en relación con este punto, el artículo de Susana Durão y Maria Claudia Coelho (2013) titulado "Moral e emocão nos movimentos culturais: Estudo da 'tecnologia social' do Grupo Cultural AfroReggae" en Revista de Antropolgia da USP. 
(algunos son de origen portugués, otros, nordestinos que están fuertemente discriminados, además de "quilombolas" 11 y de artistas recién llegados) y por marineros, prostitutas y trabajadores populares, vecambiado su perfil radicalmente, tanto por la apertura de espacios del lugar, lo que facilitaría la vigilancia y control de sus usuarios, como por el cambio de categoría de la edificación y la reurbanización de sus calles y plazas locales, o bien, por el cierre de clubes de alterne o de espacios de sociabilidad de los sectores populares.

Las políticas urbanísticas implementadas a partir del Instituto Pereira Passos (IPP) para esta área del centro de la ciudad de Río de Janeiro tiene un carácter "civilizador". Como observa el antropólogo José Reginaldo Gonçalves, especializado en la temática del patrimonio, la "cultura" viene siendo esgrimida como argumento para normalizar prácticas y conducta en la localidad. Estos argumentos salen de la cabeza de los técnicos del planeamiento urbano del municipio, en su gran mayoría arquitectos con una concepción muy propia de los usos adecuados de este espacio de la ciudad. Hablando del trabajo de su asesorada de doctorado, Roberta Guimarães (2011), sobre el mito de la Pequeña África y del Morro da Conceição, Gonçalves advierte:

Ella trabajó con varios urbanistas, entrevistándolos, y ellos tienen una determinada concepción de ese espacio. Una concepción que va a orientar los trabajos de intervención. Lo que pienso, en cuanto etnógrafo, es que los urbanistas deberían ser vistos también como una especie de tribu. Ellos también deberían ser vistos como una comunidad, compartiendo mitos, compartiendo ritos, y eso no significa descalificar el conocimiento de ellos. Por el contrario, significa calificarlo: cómo es que ese personal conoce, qué tipo de preguntas hacen, cuáles son sus presupuestos. Así como tiene sentido preguntar por la comunidad de los abogados o de los médicos. ¿Cómo incluir esa dimensión? No existe respuesta rápida. Encuentro que es un proceso político. Una cosa bien interesante, que es demostrar cómo los urbanistas operan con un determinado discurso en donde hay una marcación del tiempo, por ejemplo la Reforma Pereira Passos, como un marco fundamental en la historia dela ciudad. De hecho lo es. Pero no podemos olvidar que se trata ahí de un determinado encuadramiento de una memoria, de una determinada concepción del pasado. Dentro de ese juego de lenguaje es perfecto, es eso mismo. Pero desde el punto de vista de la población, de la memoria colectiva, no es eso lo que cuenta. Son otras demarcaciones, en términos de historia del Morro, iy eso tiene que ser considerado! Pienso, después de años lidiando con eso, es que las cosas igual se deciden en el plano de la discusión pública, de la lucha política en sus diferentes niveles. Si usted tiene una buena reflexión, un buen trabajo de investigación, eso ayuda mucho, pero garantizar buenos resultados no es seguro.

Roberta Guimarães (2013: 49-50) afirma, corroborando la observación de Gonçalves, en su artículo "O encontro mítico de Pereira Passoscom a Pequena África: narrativas de passado e formas de habitar na Zona Portuária carioca" que:

"Las memorias y formas de habitar concebidas por los planificadores se distinguían de otras tantas, y cada piedra o piso por ellos modificado era capaz de movilizar diferentes subjetividades, contranarrativas y conflictos. Como

11 N. de R.: La denominación "quilombola" se refiere a los habitantes de los quilombos que surgieron durante el coloniaje fundados por los esclavos africanos que lograban escapar y que persisten hasta hoy día como símbolo de resistencia de los pueblosde origen africano. 
efecto de sus imaginarios e intervenciones, surgían entonces en el morro otros imaginarios a ellos asociados y contrapuestos". ${ }^{12}$

Una breve incursión por el espacio reconfigurado nos presenta nuevos habitantes y frecuentadores de esa localidad. Un café vendiendo quiches y nhoques ${ }^{13}$ la reapertura de un antiguo restaurante de comida portuguesa incendiado con un visual intencionalmente retro y precios bien modernos; la destrucción de una ong que trabajaba con jóvenes de clases populares en aulas de box, casas comerciales y albergues para jóvenes turistas, etc. Sólo continúa en el "nuevo espacio" el club Kalesa que atiende a los modernos y alternativos que aspiran a una experiencia "única" ahí. Hasta la misma tradicional asociación de carnavalEscravos da Mauá, que ocupa alpié del Morro da Conceição, en el Largo de São Francisco da Prainha, perdió este año el apoyo de la Prefectura Municipal. Los habitantes del Morro da Conceiçåo ya se sienten incómodos con la turistificación del lugar promovida en los últimos tiempos. Se pueden encontrar carteles escritos por sus habitantes que avisan: "Favor de no sacar fotos de nuestra casa sin autorización". En cuanto a eso, aun en el Morro da Conceição $\mathrm{y}$ alrededores, los precios de los alquileres e inmuebles alcanzaron niveles elevados en los últimos cuatro años.

Este cuadro de modificaciones aceleradas en la ciudad de Río de Janeiro nos hace recordar el diagnóstico hecho por Manuel Delgado sobre el Foro Universal de las Culturas realizado en 2004 en Barcelona. El antropólogo afirma que la ciudad de Barcelona "vive un colosal proceso de urbanización y, como las otras veces, parece requerir algún gran evento que lo legitime simbólicamente". Para Delgado, estaría en marcha un proceso de higienización y de escamoteamiento de los conflictos en el espacio urbano con la transferencia de importantes áreas de la ciudad hacia las manos de la especulación inmobiliaria.

Los megaeventos que la ciudad de Río de Janeiro abrigará en 2014 y 2016, han servido de justificación para varias acciones de la municipalidad en el sentido de suprimir derechos de la población y abrir brecha a los intereses del sector privado,insertándola en el ámbito de las global cities analizadas por Saskia Sassen (1991). El periodo post-electoral estuvo lleno de cambios en los criterios de concesión de licencias y de fractura de categorías para la construcción de edificios y de un campo de golf, incluso en una área de protección ambiental en la Zona Oeste de Río. La justificación oficial para la liberación del área sería la permuta para construcción de un parque en otro lugar de la ciudad.Como explican Pete Fussey y Gemma Galdon Clavell (2011):

"en particular y desde 1956, con la primera mención sobre "legado" olímpico en Melbourne, ha habido una conexión explícita entre megaeventos y reconfiguración del medio urbano. En años más recientes, los megaeventos se vincularon a una serie de políticas públicas de largo plazo que trascienden al efímero "palco" del evento real y resuenan a lo largo de tiempo y del lugar. Tales políticas incluyen, generalmente, aspiraciones para la "regeneración "y una mayor "sostenibilidad" de una determinada área, y la "securitización"14 generalizada de geografías y toda una reorganización de la gobernanza urbana". ${ }^{15}$

12 GONÇAlVES, José Reginaldo santos; GUIMARÃEs, Roberta Sampaio \& BITAR, nina pinheiro. A alma das coisas: patrimônios, materialidades e ressonância. Rio de Janeiro: Mauadx/FAPERJ. 2013.

13 N. de R.: Quiche es una tarta salada de origen francés, hecha con queso, carne y vegetales; Nhoque es una pasta de origen italiano, hecha de papa, harina de sémola o trigo y huevo.

14 N. de R.: En portugués, "securitização" es un anglicismo derivado de securitization que se refiere a diversos instrumentos financieros (bonos, deuda, etc.) agrupados en un solo instrumento que puede ser negociado en el mercado de capitales.

15 FIRMINo, Rodrigo. "Cidade conectada, movimentos controlados: tecnologia, espaço e megaeventos" en Ciên- 
Me parece que la política de "Choque de Orden" y todos sus desdoblamientos sobre la población son el costo que la sociedad carioca paga por haberse vuelto parte de la "ciudades globales". En otras palabras,

“el problema es que esta presión para una violenta política de "hacer ciudad" deberá inscribir el proceso en la llave del aprovechamiento máximo siguiendo el evangelio de la economía de mercado, en la más pura óptica del capitalismoinmobiliario en sus articulaciones actualizadas con los demás mercados: del entretenimiento, del deporte, del turismo y de la cultura" (Sánchez et al., 2010).

Ojalá tengamos fisuras en ese contexto hegemónico para que los múltiples conflictos urbanos puedan contraponerse a esa dinámica dominante, para que podamos retomar la calle y sus espacios públicos. La noción de "Choque de Orden" pone de relieve una concepción muy particular y autoritaria de lo que debe ser una ciudad y sus usos. Tim Sieber (2008: 62) concluye un artículo sobre Lisboa afirmando que los etnógrafos urbanos "tal vez precisemos reconocer nuestra propia necesidad de las calles, y también, del espacio público. Al defender los derechos de los ciudadanos de las ciudades de cualquier parte del mundo, estamos finalmente defendiéndonos a nosotros mismos, y no sólo a los urbanitas que algunos de nosotros somos. En la lucha en contra de la actual privatización del dominio público en general, tenemos también que defender muchas de nuestras propias calles, y sólo algunas de ellas se sitúan en la calle". ${ }^{16}$

\section{Bibliografía}

BECKER, Howard S. Uma Teoria da Ação Coletiva. Rio de Janeiro: Zahar. 1977.

BIENENSTEIN, Glauco; MASCARENHAS, Gilmar; SÁNCHEZ, Fernanda. O jogo continua: Megaeventos esportivos e cidades. Rio de Janeiro: EdUERJ. 2010.

CAVALCANTI, Maria Laura Viveiros de Castro. Carnaval carioca: dos bastidores ao desfile. Rio de Janeiro: Funarte/UFRJ. 1994.

CORDEIRO, Graça Índias \& VIDAL, Frédéric. A Rua: espaço, tempo, sociabilidade. Lisboa: Livros Horizonte. 2008.

DELGADO, Manuel. Carrer, festa i revolta: els usos simbòlics de l'espai públic a Barcelona (19512000). - Temes d'etnologia de Catalunya; 8. Barcelona: Generalitat de Catalunya/Institut Català d'Antropologia. 2003.

Elogi del vianant: del "model Barcelona” a la Barcelona real. Barcelona: Edicions de 1984. 2005.

FIRMINO, RodRigo. "Cidade conectada, movimentos controlados: tecnologia, espaço e megaeventos" en Ciência e Cultura, Vol. 64, No 3. São Paulo, 2012.

GAFFNEY, Christopher. "Megaeventos e dinâmicassócio-espaciais no Rio de Janeiro, 1919-2016" en Journal of Latin American Geography, 9-1, 2010.

GANS, Herbert J., The Urban Villagers: Group and Class in the Life of Italian-Americans. New York: Free Press of Glencoe.1962.

GOFFMAN, Erving. A representação do eu na vida cotidiana. Petrópolis: Vozes. 1985.

GONÇALVES, José Reginaldo Santos; GUIMARÃES, Roberta Sampaio \& BITAR, nina Pinheiro. A alma das coisas: patrimônios, materialidades e ressonância. Rio de Janeiro: Mauadx/ FAPERJ. 2013.

LEFEBVRE, Henri. El derecho a La ciudad. Barcelona: Península. 1973.

cia e Cultura, Vol. 64, № 3. São Paulo, 2012.

16 SIEBER, tim. "Ruas da cidade e sociabilidade pública: umolhar a partir de Lisboa" en, GraçaÍndiasCordeiro\&Frédéric Vidal. A rua: espaço, tempo, sociabilidade, Lisboa, Livros Horizonte, 2008. 
MAKHLOUF De La GARZA, Muna. Transformaciones Urbanas desde La Resistencia: aproximaciones a um movimiento vecinal em La Barceloneta. Universidad de Barcelona: Tesis Doctoral em Antropologia Urbana. 2015.

VELHO, Gilberto. Projeto e Metamorfose. Rio de Janeiro: Jorge Zahar. 1994. e KUSCHNIR, Karina. Mediação, Cultura e Política. Rio de Janeiro: Aeroplano. 2001.

WACQUANT, Loïc. As Prisões da Miséria. Rio de Janeiro: Jorge Zahar Editor. 2001.

\section{3}

